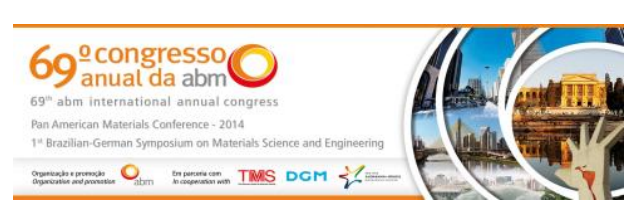

Tema: Materiais Cerâmicos, Compósitos e Poliméricos

\title{
ESTUDO COMPARATIVO DE MISTURAS DE REJEITOS INDUSTRIAIS PARA PRODUÇÃO DE MATÉRIA PRIMA CERÂMICA*
}

\section{Resumo}

\author{
Angel Rafael Arce Chilque ${ }^{1}$ \\ Anderson Alves Cunha ${ }^{2}$ \\ Francismar Henrique de Oliveira ${ }^{3}$ \\ Leandro César Silva Vieira ${ }^{4}$
}

Este trabalho tem por objetivo estudar a relação da escória (coproduto da siderurgia) com a lama (rejeito da mineração de ferro), visando a utilização da mistura destes como insumo na construção civil particularmente na confecção de tijolos, mitigando impactos ambientais gerados pela extração de argila. $O$ estudo envolveu a realização de ensaios de caracterização química e granulométrica da escória, lama e argila, compactação e modelagem da mistura, queima, absorção de água, cálculo de porosidade aparente e características geométricas dos tijolos confeccionados e determinação de resistência à compressão dos mesmos. Os resultados mostraram que não existe uma relação simples entre a resistência a compressão e a porosidade, indicando com isto que outros fatores devem ser considerados no controle da resistência à compressão.

Palavras-chave: Cerâmica; Escória; Lama.

\section{COMPARATIVE STUDY OF MIXED WASTE FOR INDUSTRIAL PRODUCTION OF CERAMIC RAW MATERIAL}

\section{Abstract}

This work aimed to study the relationship of the slag (byproduct of steel) with mud (waste from mining), seeking to use a mixture of these as input in the construction industry particularly in the manufacture of bricks, mitigating environmental impacts generated by the extraction of clay. The study involved the testing of chemical characterization and particle size of the slag, mud and clay, compression and modeling of the mixture, burn, water absorption, calculation of apparent porosity and geometrical characteristics of the bricks made and determination of the compression resistance of the materials. The results showed that there is no simple relation between compressive strength and porosity, indicating by this that other factors must be considered in the control of the compressive strength.

Keywords: Ceramics; Slag; Mud.

1 Prof. MSc Dr. es Sciences Paris VI, Universidade do Estado de Minas Gerais, João Monlevade, MG, Brasil.

2 Bacharel em Engenharia Metalúrgica, Universidade do Estado de Minas Gerais, João Monlevade, MG, Brasil.

3 Bacharel em Engenharia Metalúrgica, Universidade do Estado de Minas Gerais, João Monlevade, MG, Brasil.

4 Bacharel em Engenharia Metalúrgica, Universidade do Estado de Minas Gerais, João Monlevade, MG, Brasil.

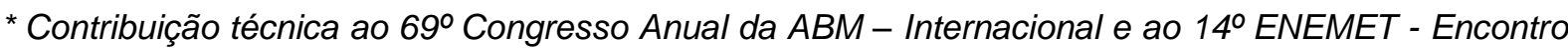
Nacional de Estudantes de Engenharia Metalúrgica, de Materiais e de Minas, 21 a 25 de julho de 2014, São Paulo, SP, Brasil.
} 


\section{INTRODUÇÃO}

A História do Brasil está intimamente relacionada com a busca e a utilização dos seus recursos minerais, que sempre contribuíram com importantes insumos para a economia mundial, fazendo parte da ocupação territorial e da história nacional. Todavia, no caminho da produção de bens de origem mineral é preciso responsabilidade para que o aproveitamento dos recursos minerais seja realizado de forma racional, controlada e sustentável, resultando em benefício para toda a sociedade [1].

As empresas têm se conscientizado de modo a exercerem suas atividades, desde a extração de um bem mineral até o seu destino final (após sua utilização), de modo sustentável, porém, ainda assim, grandes desafios são encontrados no aprimoramento desta atividade fundamental para o desenvolvimento do país. Entre estes desafios o mais expressivo, é sem dúvida, o controle e destino dos resíduos gerados. A substituição de matérias-primas naturais por resíduos pode configurar uma oportunidade para melhorar a gestão de recursos. As taxas elevadas de produção se traduzirão em um aumento significativo de resíduos e, para as indústrias dispostas a utilizá-los, estes últimos poderão constituir uma fonte de matéria-prima barata e renovável [2].

O resíduo proveniente do beneficiamento de minério de ferro, em geral possui sílica, hidróxidos e óxidos de ferro, este possivelmente atuará bem em sua função como aglomerante. O resíduo sólido proveniente da siderurgia (escória de alto-forno) atuará basicamente como grânulos, que irão compor o produto. Para que a reação entre aglomerante e grânulos ocorra é necessário elevar esse conjunto a determinadas temperaturas.

As escórias de alto-forno são resíduos inevitáveis na produção de ferro-gusa, são resultado da combinação da ganga do minério de ferro com as cinzas do coque e do calcário. A atividade hidráulica da escória depende de vários fatores, sendo 0 sistema de resfriamento um deles. Uma escória com composição química e grau de vitrificação adequado, quando misturada com água poderá hidratar-se e cristalizarse, promovendo então o endurecimento do conglomerado [3].

Os rejeitos de mineração apresentam características mineralógicas, geotécnicas e físico-químicas variáveis, em função do tipo de minério e do próprio processo de beneficiamento adotado. Os rejeitos finos são materiais, em geral, constituídos basicamente das frações silte e argila. Convencionalmente são depositados em forma de lama, e transportados por tubulações até as barragens de rejeito [4].

A presente pesquisa de caráter exploratório, tem como objetivo avaliar a viabilidade técnica do reaproveitamento em conjunto de resíduos e coprodutos da mineração e da siderurgia, visando o emprego da junção destes na fabricação de tijolos cerâmicos, matéria prima para a construção civil.

\section{MATERIAIS E MÉTODOS}

Neste tópico serão abordados os materiais utilizados (lama, escória e argila) e a metodologia empregada para fabricação do tijolo. Os ensaios de caracterização física e química da lama e escória foram realizados nas dependências das próprias instituições doadoras seguindo as normas da ABNT. A argila foi caracterizada no laboratório de Tratamento de Minérios da Faculdade de Engenharia da UEMG.

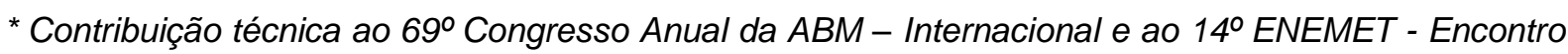
Nacional de Estudantes de Engenharia Metalúrgica, de Materiais e de Minas, 21 a 25 de julho de 2014, São Paulo, SP, Brasil.
} 


\subsection{Escória de Alto-Forno, Lama (Rejeito da Mineração de Ferro) e Argila}

A escória empregada foi doada pela Arcelor Mittal unidade de João Monlevade-MG, a mesma é denominada granulada devido ao tipo de resfriamento com jatos de água. Na tabela 1 está apresentada a composição química da escória.

Tabela 1. Composição química da escória

\begin{tabular}{cccccccc}
\hline Composição & $\mathrm{FeO}$ & $\mathrm{MgO}$ & $\mathrm{SiO}_{2}$ & $\mathrm{Al}_{2} \mathrm{O}_{3}$ & $\mathrm{CaO}$ & $\mathrm{MnO}$ & $\mathrm{H}_{2} \mathrm{O}$ \\
\hline$(\%)$ & 0,50 & 6,19 & 35,60 & 10,80 & 44,5 & 0,48 & 6,90 \\
\hline
\end{tabular}

A lama utilizada foi proveniente da Samarco Mineração unidade de Mariana-MG. A tabela 2 exemplifica a composição química da lama.

Tabela 2. Composição química da lama

\begin{tabular}{cccccc}
\hline $\mathrm{Fe}$ & $\mathrm{SiO} 2$ & $\mathrm{Al} 2 \mathrm{O} 3$ & $\mathrm{P}$ & $\mathrm{PPC}$ & $\mathrm{MnO} 2$ \\
\hline 50,77 & 18,24 & 2,66 & 0,104 & 6,14 & 0,14 \\
\hline
\end{tabular}

A argila foi trazida de Pedro Leopoldo-MG, a sua composição química está apresentada tabela 3.

Tabela 3. Composição química da argila

\begin{tabular}{ccccccccc}
\hline Composição & $\mathrm{SiO}_{2}$ & $\mathrm{Al}_{2} \mathrm{O}_{3}$ & $\mathrm{MgO}$ & $\mathrm{Fe}_{2} \mathrm{O}_{3}$ & $\mathrm{TiO}_{2}$ & $\mathrm{CaO}$ & $\mathrm{MnO}$ & $\mathrm{K} 2 \mathrm{O}$ \\
\hline$(\%)$ & 62,97 & 20,79 & 0,56 & 3,83 & 0,16 & 0,47 & 0,05 & 2,28 \\
\hline
\end{tabular}

\subsection{Metodologia}

A metodologia consistiu em pesquisa bibliográfica geral; planejamento do trabalho; obtenção das amostras; tratamento das amostras (secagem, moagem e classificação); construção de uma prensa hidráulica para compactação das massas; fabricação dos tijolos (compactação e modelagem da mistura escória/lama/argila bem como a sua queima em forno específico), além da realização de ensaios físicos e mecânicos nos tijolos fabricados, seguindo normas da ABNT.

\subsubsection{Preparação das matérias primas}

\subsubsection{Escória de alto forno}

Após a obtenção da amostra de escória realizou-se a secagem natural, em sequência o material foi destorroado e moído em moinhos de bolas. Logo em seguida foi efetuado o peneiramento, objetivando utilizar uma fração com $100 \%$ passante na malha de $250 \mu \mathrm{m}$. O material foi armazenado em sacos plásticos e etiquetado, para a posterior utilização nas formulações das misturas.

\subsubsection{Lama}

Após obtenção da amostra de lama, essa passou por um processo de secagem em estufa à $100^{\circ} \mathrm{C}$ durante 24 horas. Em seguida, essa matéria foi processada no moinho de bola e classificada em peneiras com objetivo de utilizar uma fração com $100 \%$ passante na malha de $250 \mu \mathrm{m}$.

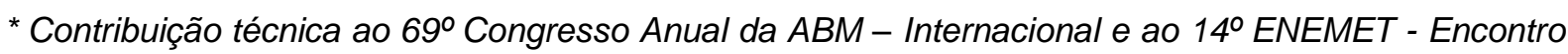
Nacional de Estudantes de Engenharia Metalúrgica, de Materiais e de Minas, 21 a 25 de julho de 2014, São Paulo, SP, Brasil.
} 


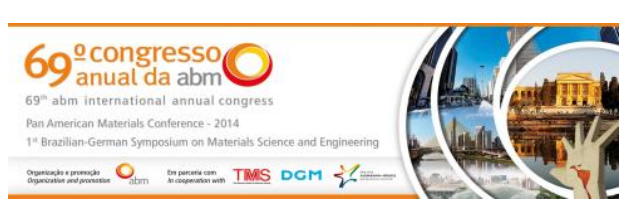

produto. A obtenção das propriedades finais tem relação com as complexas transformações físicas e químicas que ocorrem durante a queima [5].

\section{RESULTADOS E DISCUSSÃO}

\section{1 Índice de Absorção de Água}

O índice de absorção de água é um fator chave no efeito da durabilidade do tijolo, portanto foi decidido realizar o ensaio seguindo como normas de referência a NBR 8491 [6] e NBR 8492 [7].

Seguindo os parâmetros fixados, primeiramente determinou-se a massa seca dos corpos de prova, submetendo estes a secagem em estufa a $105^{\circ} \mathrm{C}$ durante 24 horas. Logo após essa determinação os corpos de prova foram colocados em um recipiente de dimensões apropriadas, preenchido com água à temperatura ambiente, em volume suficiente para mantê-los totalmente imersos, como pode ser visto na Figura 1, permanecendo nestas condições por 24 horas.

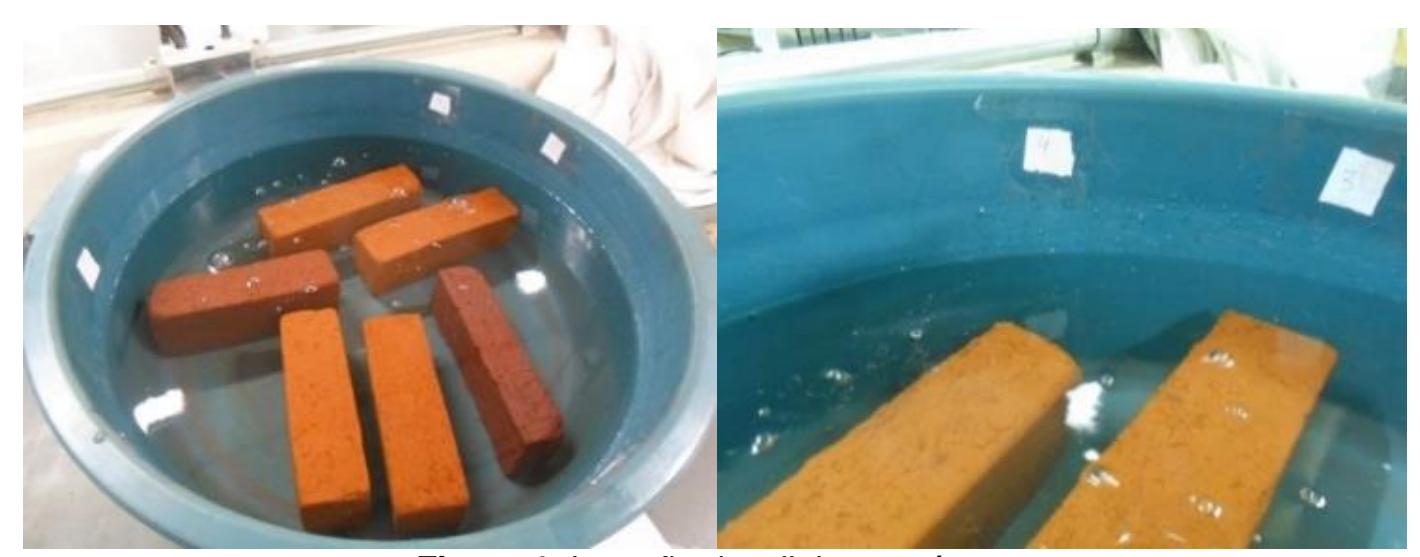

Figura 1. Imersão dos tijolos em água.

Segundo a NBR 8491, os valores individuais do índice de absorção de água não devem ser superiores a $22 \%$. Este índice é determinado pela equação 1:

Onde:

$$
A A(\%)=\frac{m u-m s}{m s} \times 100
$$

mu corresponde a massa úmida do corpo de prova, e

$\mathrm{m}_{\mathrm{s}}$ representa a massa seca do corpo de prova, expressa em gramas.

Os resultados deste índice são demonstrados na Figura 2. Pode-se inferir que todos os grupos de mistura apresentaram resultados melhores comparando com o grupo padrão (100\% argila), porém só os grupos II (100\% Lama), III (80\% Argila e $20 \%$ Lama) e XI (20\% Argila, 60\% Lama e 20\% Escória) atenderam a especificação da ABNT NBR 8492.

\footnotetext{
* Contribuição técnica ao $69^{\circ}$ Congresso Anual da ABM - Internacional e ao 14ํㅡㄹ ENEMET - Encontro Nacional de Estudantes de Engenharia Metalúrgica, de Materiais e de Minas, 21 a 25 de julho de 2014, São Paulo, SP, Brasil.
} 


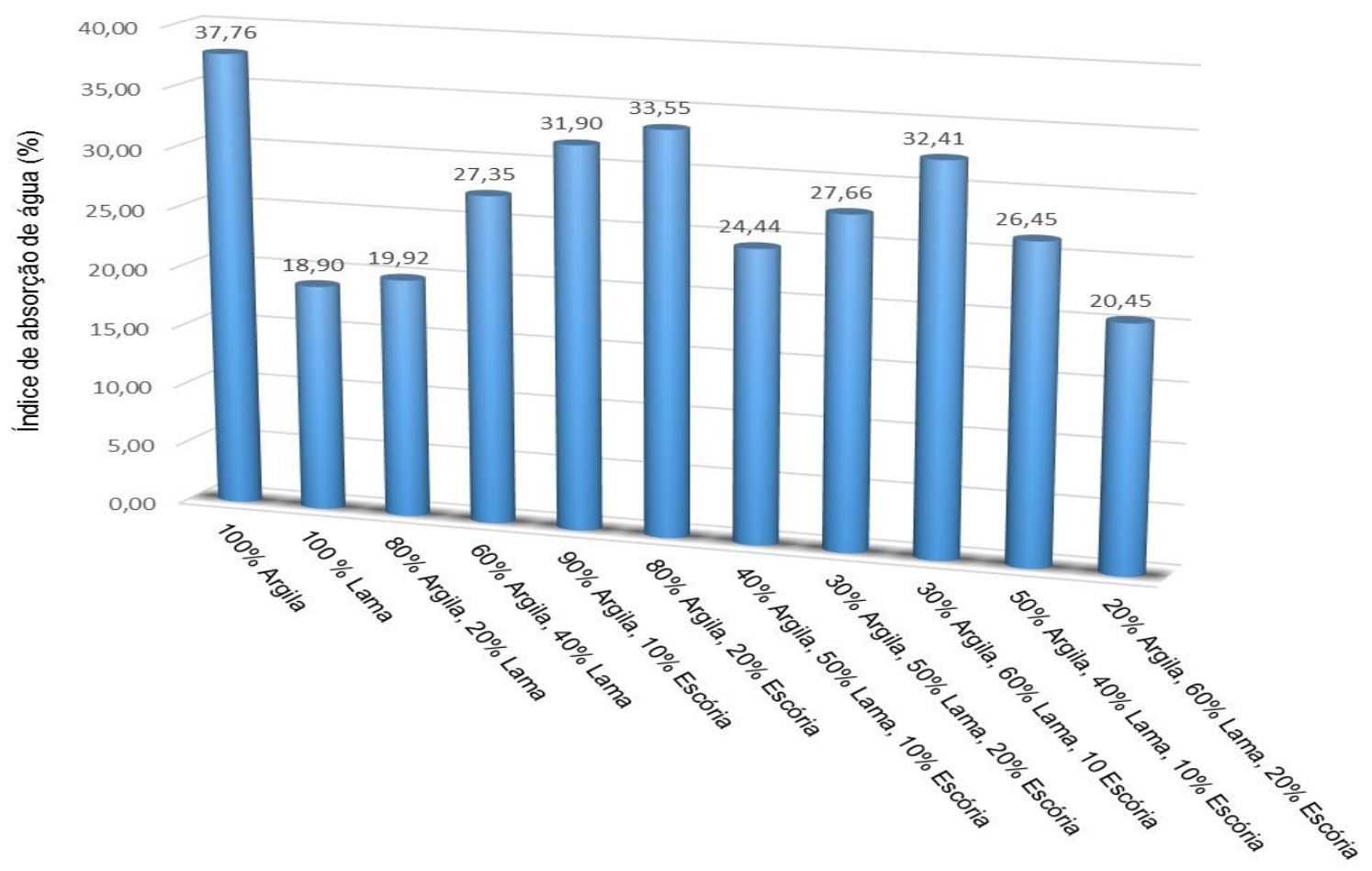

Figura 2. Gráfico dos resultados de índice de absorção de água.

\subsection{Influência da Porosidade}

Para a obtenção da porosidade aparente, o procedimento baseia-se na determinação da massa da amostra seca $\left(\mathrm{M}_{\mathrm{s}}\right)$, das massas úmidas $\left(\mathrm{Mu}_{\mathrm{u}}\right.$ e e imersas $(\mathrm{Mi})$, segundo a equação da Balança de Arquimedes (Equação 2):

\section{Onde:}

$$
P_{a p}=\left(\frac{M_{u}-M_{s}}{M_{u}-M_{i}}\right) \times 100
$$

Pap é a porosidade aparente,

Mu é a massa úmida,

$M_{s}$ é a massa seco e,

Mi é massa imersa no líquido.

O ensaio foi realizado em duplicata, desse modo, o grupo com menor absorção de água, grupo II (100\% lama), foi o grupo que apresentou o menor índice de porosidade (tabela 5), resultado este que está condizente com a literatura consultada [8]. 


\begin{tabular}{|c|c|c|c|c|}
\hline \multicolumn{5}{|c|}{ 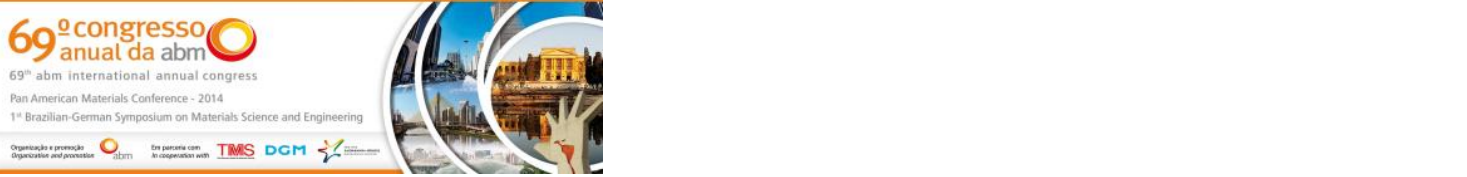 } \\
\hline \multicolumn{5}{|c|}{ Tabela 5. Porosidade (\%). } \\
\hline Grupo & $\begin{array}{c}\text { Corpo de } \\
\text { prova }\end{array}$ & $\begin{array}{c}\text { Massa imersa } \\
(\mathrm{g})\end{array}$ & $\begin{array}{l}\text { Porosidade } \\
\text { aparente (\%) }\end{array}$ & $\begin{array}{c}\text { Porosidade } \\
\text { aparente média (\%) }\end{array}$ \\
\hline \multirow{2}{*}{ I } & 01 & 800,00 & 66,67 & \multirow{2}{*}{67,26} \\
\hline & 02 & 800,00 & 67,86 & \\
\hline \multirow{2}{*}{ II } & 01 & 600,00 & 23,21 & \multirow{2}{*}{23,51} \\
\hline & 02 & 540,00 & 23,81 & \\
\hline \multirow{2}{*}{ III } & 01 & 800,00 & 35,00 & \multirow{2}{*}{35,00} \\
\hline & 02 & 860,00 & 35,00 & \\
\hline \multirow{2}{*}{ IV } & 01 & 760,00 & 44,44 & \multirow{2}{*}{44,44} \\
\hline & 02 & 780,00 & 44,44 & \\
\hline \multirow{2}{*}{ V } & 01 & 840,00 & 64,29 & \multirow{2}{*}{64,59} \\
\hline & 02 & 880,00 & 64,89 & \\
\hline \multirow{2}{*}{ VI } & 01 & 840,00 & 61,29 & \multirow{2}{*}{62,10} \\
\hline & 02 & 880,00 & 62,91 & \\
\hline \multirow{2}{*}{ VII } & 01 & 860,00 & 45,71 & \multirow{2}{*}{45,58} \\
\hline & 02 & 940,00 & 45,45 & \\
\hline \multirow{2}{*}{ VIII } & 01 & 720,00 & 40,48 & \multirow{2}{*}{40,43} \\
\hline & 02 & 728,00 & 40,38 & \\
\hline \multirow{2}{*}{ IX } & 01 & 860,00 & 63,33 & \multirow{2}{*}{63,67} \\
\hline & 02 & 900,00 & 64,00 & \\
\hline \multirow{2}{*}{$X$} & 01 & 820,00 & 45,71 & \multirow{2}{*}{45,71} \\
\hline & 02 & 840,00 & 45,71 & \\
\hline \multirow{2}{*}{$X I$} & 01 & 760,00 & 32,56 & \multirow{2}{*}{32,56} \\
\hline & 02 & 820,00 & 32,56 & \\
\hline
\end{tabular}

O gráfico da Figura 3 correlaciona este aumento da absorção de água em função da porosidade calculada. Nota-se a partir desse gráfico uma alta relação da absorção de água com a porosidade. O coeficiente de determinação $\mathrm{R}^{2}$ relativamente alto $(0,9004)$ confirma essa alta relação entre as variáveis e demonstra que apenas $10 \%$ do valor da absorção de água não depende desta variável. Fato este que certifica uma boa técnica operacional empregada na pesquisa.

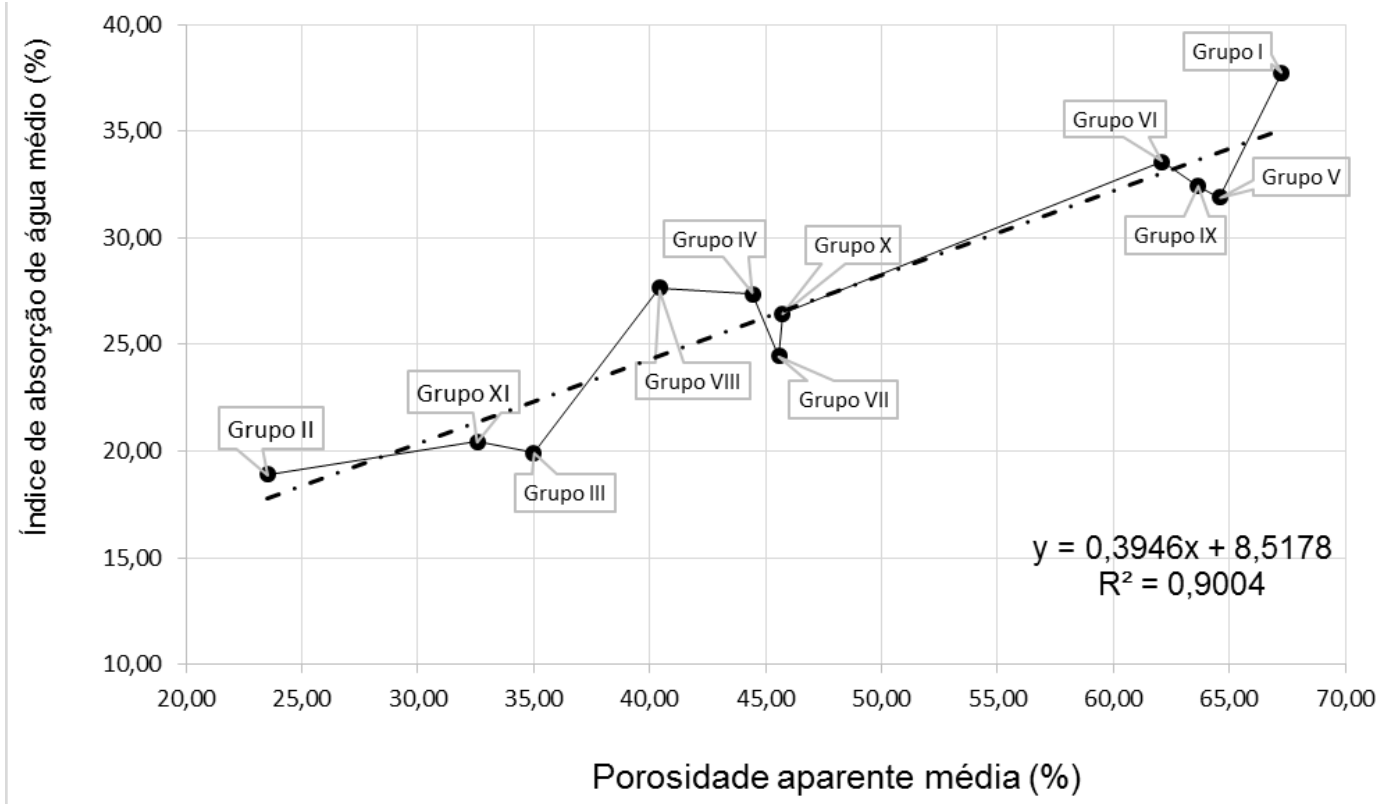

Figura 3. Gráfico da tendência de aumento da absorção de água X porosidade.

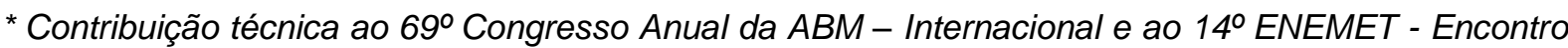
Nacional de Estudantes de Engenharia Metalúrgica, de Materiais e de Minas, 21 a 25 de julho de 2014, São Paulo, SP, Brasil.
} 


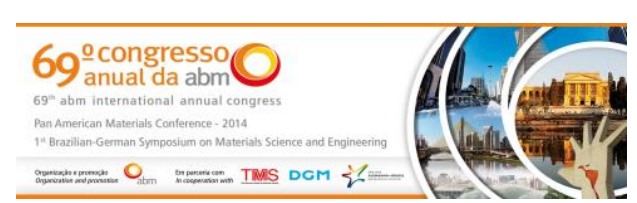

\subsection{Determinação da Resistência à Compressão Mínima}

Os blocos prensados e queimados devem seguir a norma NBR 6460, para determinação da resistência a compressão [9]. O teste de compressão dos tijolos foi realizado no laboratório de materiais de construção civil da UNIFEI campus Itabira e apresentou os resultados que podem ser visualizados no gráfico da Figura 4.

Pode-se inferir que todos os grupos de mistura atenderam a especificação da norma ABNT NBR 8492, situando entre as classes B e C da referida norma, como pode ser visto no gráfico. Os grupos que apresentaram maior resistência a compressão foram os grupos V (90\% argila e 10\% escória) e VI ( $80 \%$ argila e $20 \%$ escória), evidenciando que a escória moída é benéfica para esta propriedade.

Os grupos que continham lama obtiveram resistência similar ao grupo padrão, situando entre as classes da norma, evidenciando que seu uso não prejudica a resistência a compressão dos tijolos maciços, podendo ser usada na formulação desses tijolos.

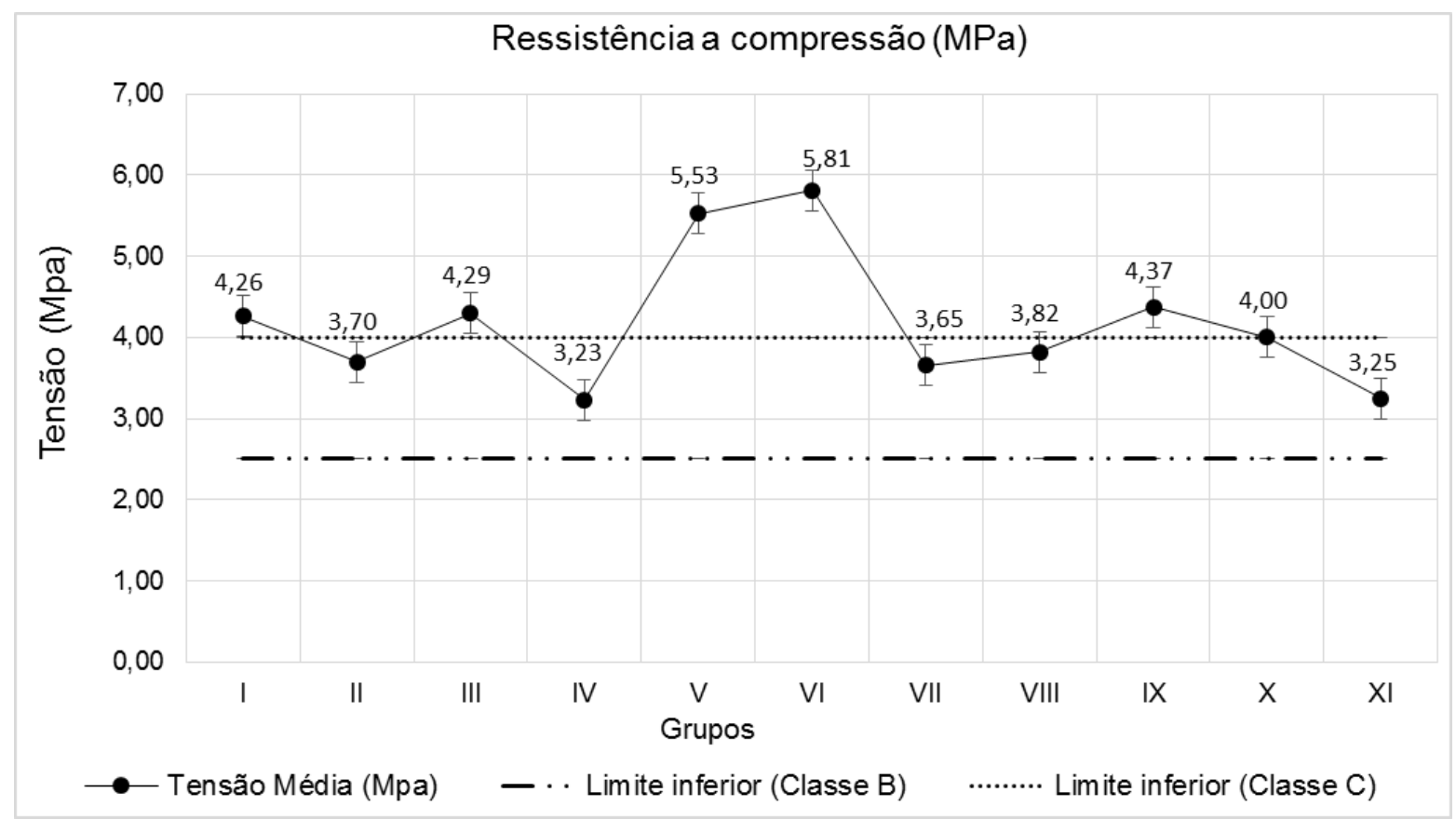

Figura 4. Gráfico do resultado do teste de compressão.

\subsection{Microscopia Óptica}

Os resultados das micrografias, mostraram diferentes formas, tamanho e distribuição dos grão, com consequente porosidade. Pode-se notar que as superfícies não se apresentaram completamente vítreas, o que possivelmente interferiu negativamente nos resultados do índice de absorção de água, evidenciando que a compactação e queima não foram satisfatórias para união das partículas, como pode ser visto na figura 5, que é uma microfotografia do grupo V (90\% Argila, 10\% Escória).

\footnotetext{
* Contribuição técnica ao $69^{\circ}$ Congresso Anual da ABM - Internacional e ao 14ํㅡㄹ ENEMET - Encontro Nacional de Estudantes de Engenharia Metalúrgica, de Materiais e de Minas, 21 a 25 de julho de 2014, São Paulo, SP, Brasil.
} 

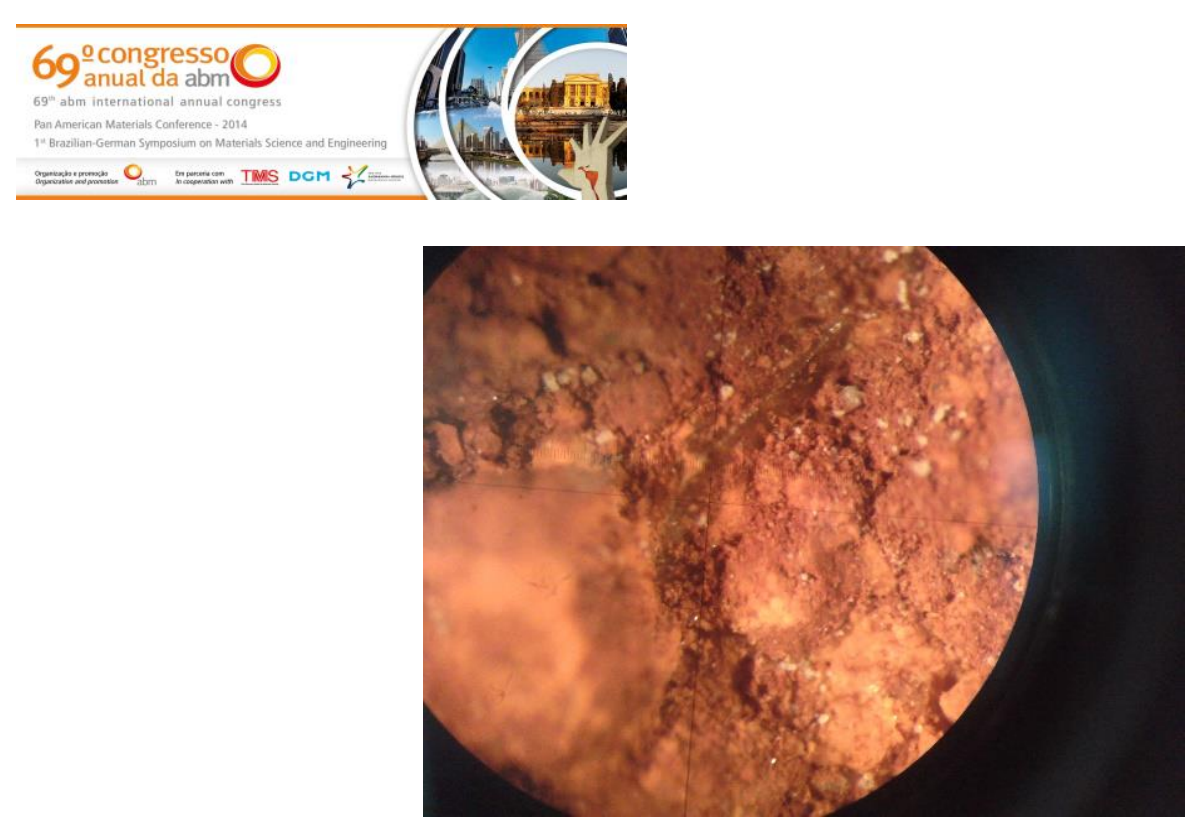

Figura 5. Microscopia do grupo V.

\section{CONCLUSÃO}

Os resultados obtidos no presente trabalho exploratório, permitem concluir que a metodologia e procedimentos empregados, foram satisfatórios, com resultados coerentes inclusive quando comparado com estudos realizados por outros autores, como Silva [1] Groenner [10] e Pinto [11].

Foi possível a obtenção de corpos cerâmicos a partir das formulações efetuadas. A adição dos resíduos de lama e escória se mostrou satisfatória para o índice de absorção de água, visto que todos os grupos experimentais apresentaram melhores resultados que o padrão (100\% Argila).

Para a resistência a compressão as adições dos resíduos também foi satisfatória, sendo que os tijolos que continham somente escória como resíduo e matriz de argila apresentaram valores de resistência maiores. Esta melhora está relacionada com os tratamentos (moagem e classificação) dos materiais utilizados. Em trabalho anterior similar com a adição de escória nas mesmas proporções, porém sem moagem e classificação prévia, a resistência a compressão foi relativamente baixa; isto mostra a importância de se trabalhar com granulometria mais controlada [12].

Os grupos contendo lama obtiveram resistência similar ao grupo padrão, porém esta adição melhorou o índice de absorção de água tornando-se desta forma benéfica.

A substituição parcial da argila pelos materiais estudados é em geral benéfica, porém os elevados índices de absorção de água e porosidade indicam que outros estudos complementares devem ser efetuados visando o melhoramento das técnicas aqui empregadas.

Os resultados aqui apresentados mostram que a relação entre a resistência a compressão e a porosidade não é simples, indicando com isto que outros fatores devem ser considerados no controle da resistência à compressão. O comportamento do material também deve ser alvo de enfoque, principalmente se tratando de análise de fissuras.

O presente trabalho permite o desdobramento de uma série de outros estudos, envolvendo a otimização da granulometria das matérias-primas, influência de aditivo (cal) na conformação dos tijolos, melhor controle do estado superficial dos tijolos para evitar o eventual início e propagação de fissuras, a otimização do controle das variáveis operacionais relacionadas à prensagem e de tratamento térmico de recozimento e o uso de técnicas de microscopia eletrônica e de raios- $X$ para aprofundar a caracterização dos materiais.

\footnotetext{
* Contribuição técnica ao 69ำ Congresso Anual da ABM - Internacional e ao 14ํㅡㄹ ENEMET - Encontro Nacional de Estudantes de Engenharia Metalúrgica, de Materiais e de Minas, 21 a 25 de julho de 2014, São Paulo, SP, Brasil.
} 


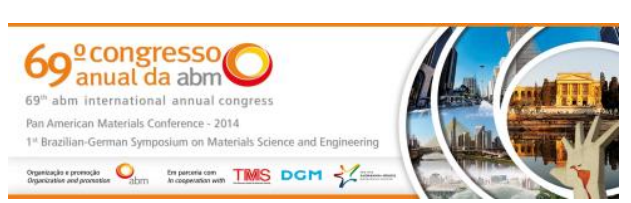

O reaproveitamento desses rejeitos evita a extração de matérias primas virgens da natureza, principalmente da argila, matéria prima essencial na formulação dos tijolos comercializados. A metodologia aqui empregada leva a resultados cuja interpretação deve considerar os valores obtidos como tendência de comportamento e não como valores absolutos.

\section{Agradecimentos}

Ao Prof. M.Sc. Dr. Angel Rafael Arce Chilque, orientador deste trabalho, pela confiança, apoio e orientação. Ao Professor Dr. Carlos Augusto Oliveira e a toda equipe do laboratório de Materiais de Construção Civil da UNIFEI campus de Itabira, pela disponibilidade de infraestrutura e equipamento para realização do teste de resistência a compressão. À FAPEMIG, pela concessão de bolsas de iniciação cientifica, referentes ao edital 06/2012, com duração de 01/03/2013 a 28/02/2014.

\section{REFERÊNCIAS}

1 Silva JG. Análise do ciclo de vida de tijolos prensados de escória de alto-forno [dissertação de Mestrado]. Vitória: Centro Tecnológico, UFES; 2005.

2 Souza Filho ML. A utilização de co-produtos da siderurgia e da indústria de beneficiamento de rochas ornamentais na produção de tijolos prensados [dissertação de Mestrado]. Vitória: Universidade Federal do Espírito Santo; 2005.

3 Massucato CJ. Utilização de escória de alto forno à carvão vegetal como adição no concreto [dissertação de mestrado]. Campinas: Universidade Estadual de Campinas; 2005.

4 Lima LMK. Retroanálise da Formação de um Depósito de Rejeitos Finos de Mineração Construído Pelo Método Subaéreo. Ouro Preto: Universidade Federal de Ouro Preto; 2006.

5 Pureza JCC. Utilização de resíduos industriais de baixa granulometria em massas cerâmicas de argila vermelha: aspectos tecnológicos e ambientais. Porto Alegre: Universidade Federal do Rio Grande do Sul; 2004.

6 Associação Brasileira de Normas Técnicas. NBR 8491: Tijolo maciço de solo-cimento Especificação. Rio de Janeiro; 1984.

7 Associação Brasileira de Normas Técnicas. NBR 8492: Tijolo maciço de solo-cimento Determinação da resistência à compressão e da absorção d'água. Rio de Janeiro; 1984.

8 Pereira MM, Vasconcelos WL Processamento de cerâmicas. Belo Horizonte: Departamento de Engenharia Metalúrgica e de Materiais, Universidade do Estado de Minas Gerais; 2012.

9 Associação Brasileira de Normas Técnicas. NBR 6460: Tijolo maciço cerâmico para alvenaria - Verificação da resistência a compressão - Método de ensaio. Rio de Janeiro; 1983.

10 Groenner PEM. Reaproveitamento do resíduo de fabricação de consumíveis para soldagem em tijolos de cerâmica vermelha [tese de Mestrado]. Belo Horizonte: Universidade Federal de Minas Gerais; 2007

11 Pinto PC. Investigação de Parâmetros do CCR com Incorporação de Escória Granulada de Alto Forno para Utilização como Base de Pavimentos [dissertação de Mestrado]. São Paulo: Universidade de São Paulo; 2010.

12 Cunha AA, Oliveira FH. Estudo sobre o uso de misturas de rejeitos siderúrgicos e de mineração em específicos produtos da indústria de construção civil [projeto de pesquisa]. João Monlevade: FaEnge, UEMG; 2012.

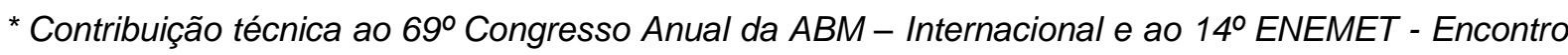
Nacional de Estudantes de Engenharia Metalúrgica, de Materiais e de Minas, 21 a 25 de julho de 2014, São Paulo, SP, Brasil.
} 